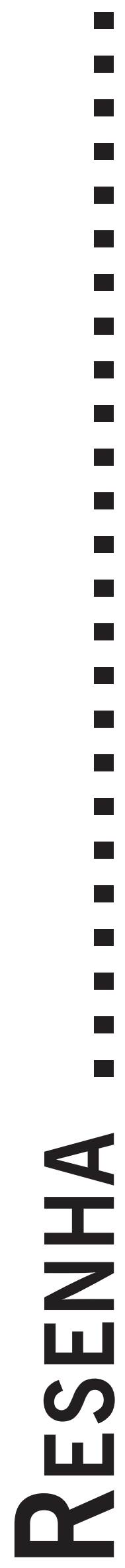




\title{
ANÁLISE DA ESCOLHA PROFISSIONAL
}

\author{
Magnan, Vanessa da Cunha e Feijoo, Ana Maria Lopes Calvo de. (2013). \\ Análise da escolha profissional. - 1. ed. - Rio de Janeiro: Edições IFEN. 152 p.
}

Severino Ramos Lima de Souza* Bruno Robson de Barros Carvalho* Alisson de Meneses Pontes*

O livro Análise da Escolha Profissional, escrito pelas psicólogas Vanessa Magnan e Ana Feijoo, problematiza e discute o tema da escolha profissional a partir das perspectivas arraigadas na psicologia desde o seu nascimento enquanto ciência independente. Segundo o filósofo Alexandre Marques Cabral, autor do prefácio, as autoras lançam um olhar crítico sobre como a psicologia moderna esteve, e ainda está, a cargo de um viés tecnicista ao lidar com a demanda da escolha profissional.

O livro inicia, exatamente, com a crítica à psicologia moderna e ao modo dicotômico com o qual, usualmente, a mesma opera por estar impregnada de concepções derivadas das filosofias da subjetividade, as quais posicionam o sujeito como ente destacado e em contraposição ao mundo. Neste modelo o ser humano é considerado como dotado de interioridade, de um mundo intrapsíquico que o determina.

No bojo dessa tradição, da qual a psicologia é herdeira, as questões relativas à escolha profissional, via de regra, têm sido discutidas como um atributo do sujeito, no âmbito de sua interioridade, cabendo ao "orientador" a responsabilidade de conduzir o orientando, mediante a aplicação de técnicas, à escolha daquela profissão que mais se adéque ao seu perfil, compreendido como um conjunto de características de personalidade e habilidades comportamentais. Portanto, esse modelo de orientação baseada em instrumentos mensuráveis, permite descobrir o que há de latente na interioridade daquele que está indeciso, afim de mobilizar seu potencial escondido, podendo assim orientar ou indicar sua escolha.

Considerando o exposto, concebe-se que o processo da escolha profissional é conduzido como "orientação vocacional", ou seja, como uma técnica dominada por um especialista (psicólogo ou pedagogo) que visa direcionar a pessoa do orientando para "atender ao chamado" para o qual está "pré-destinado", para a escolha da "profissão

Doutorandos do Programa de Pós-Graduação em Psicologia Clínica da Universidade Católica de Pernambuco. certa”, com mínima margem de erro possível, reduzindo as chances de arrependimento posterior.

Seguindo este caminho, no primeiro capítulo, as autoras abordam as diferentes concepções e classificações teóricas em torno da prática da orientação vocacional, seja com foco no sujeito, dando ênfase ao autoconhecimento e ao psiquismo, seja com foco no social, respaldada numa visão sócio-histórica.

Por conseguinte, Magnan e Feijoo propõem uma nova classificação a partir da qual intencionam falar da Análise da Escolha Profissional, dando destaque para o que cada uma delas enfatizam, a saber, o psiquismo ou o social para, em seguida apresentarem a proposta com foco na existência.

Para as autoras, as perspectivas em orientação vocacional/profissional que põem em relevo o psiquismo são "todas aquelas posições que a ênfase se encontra na noção de sujeito, sendo este compreendido como estrutura psíquica, e se considerando a ideia de potencialidade, interioridade, aptidão, personalidade, interesse, dentre outras" (p. 33). Aqui, as autoras situam e descrevem os modus operandi das abordagens psicométrica, a clínica de Bohoslavsky e a clínica da Gestalt-terapia.

Na orientação vocacional/profissional cuja ênfase recai no social, há o reconhecimento de que a escolha profissional se dá por influência das organizações sociais e que a subjetividade se constitui mediante processos e determinações sociais, abolindo qualquer noção de aptidão como algo subjacente em favor da compreensão de homem como resultado de processos históricos. Vygotsky é citado como principal teórico representante da abordagem sócio-histórica, para quem o humano constitui-se na relação com o outro social. Esta perspectiva, em psicologia, rejeita a concepção da existência de uma natureza humana em favor da afirmação da condição, sendo o homem um ser ativo, social e histórico, compreendido apenas quando inserido no social e na história que o determina e dá sentido à sua singularidade. 
Nesta perspectiva, o trabalho de orientação vocacional/profissional tem por objetivo oferecer condições para que a própria pessoa reflita sobre si e sua situação/contexto e, assim, possa decidir entendendo de forma mais aprofundada as determinações de sua escolha.

Para as autoras, as perspectivas até aqui apresentadas saem de um extremo para outro, ora com foco no sujeito como interioridade, ora com foco no social. No entanto, vale ressaltar que elas, em momento nenhum, negam a eficácia das técnicas modernas, mas esclarecem que estes modos se fundam em noções de autoconhecimento e estrutura psíquica, para então sugerir uma perspectiva com foco na existência, na qual as dicotomias entre homem e mundo, interior e exterior, psíquico e social são superadas a partir da compreensão mesma da existência como "uma experiência que se dá em um espaço cooriginário (copertença), no qual o existente e o social se constituem sempre em jogo, ou seja, como diz o filósofo no aí, no mundo" (p. 64. Grifo do autor).

O fundamento teórico-metodológico no qual as autoras se inspiram para apresentarem a possibilidade de uma orientação profissional com foco na existência é a fenomenologia-hermenêutica heideggeriana. Com a adoção de uma atitude fenomenológica busca-se o esforço de, frente ao fenômeno, poder recuar um passo atrás, colocando entre parênteses todas as teorizações e pressuposições em torno do fenômeno em questão. Com a hermenêutica, considera-se que toda e qualquer interpretação encontra-se comprometida com o horizonte histórico no qual estamos inseridos. Pontuam as autoras: "Em uma perspectiva existencial, a atuação do analista no que diz respeito à escolha profissional consiste em poder devolver ao analisando a responsabilidade frente a sua existência, em um acompanhamento implicado" (p. 67. Grifos do autor.).

No capítulo dois há um aprofundamento em torno das bases filosóficas e literárias para se pensar na possibilidade lançada da escolha profissional com ênfase na existência. Nesse sentido, de modo sintético e esclarecedor, são revisitadas algumas elaborações filosóficas de Edmund Husserl e de Martin Heidegger como fio condutor do modo de como podemos refletir sobre questões referentes ao homem, ao mundo, à verdade, ao cuidado e ao processo de decidir e escolher. Neste percurso as autoras, paulatinamente, vão desconstruindo algumas noções e concepções enraizadas na psicologia moderna.

As contribuições trazidas pelo pensamento husserliano para a psicologia estão atreladas à intencionalidade da consciência através da qual supera-se a dicotomia entre homem e mundo contida na proposta cartesiana que concebe uma subjetividade nuclear, solipsista e posicionadora do mundo. Para Husserl, a consciência é imanente, sempre aberta, recusando a ideia da consciência substancializada, localizada na interioridade. Consciência é sempre consciência de alguma coisa e, por isso, não há lugar a hipostasias.
Em Heidegger as autoras irão encontrar contribuições preciosas. Apresentam a fenomenologia-hermenêutica ou analítica existencial como o caminho tomado pelo filósofo na abordagem das questões em relação ao sentido do ser. Nesse percurso, após recuperarem o sentido originário de fenomenologia, é-nos apresentada a ideia de verdade (Alethéia) como o modo próprio de apresentação dos entes e não como representação ou adequação, e como pertencente à constituição fundamental do ser-aí. Ser-aí, no pensamento heideggeriano, indica a impossibilidade radical de se separar o ser do seu mundo (o aí), entendido como horizonte de sentido, a partir do qual a existência pode ser compreendida/interpretada. Sendo o modo de ser do ser-aí sempre ser-no-mundo, não mais dicotomizado e nem detentor de uma interioridade psíquica, ele estará sempre empenhado na tarefa de cuidar de ser, seja no modo do cuidado/descuidado com as coisas intramundanas (ocupação), seja com os outros semelhantes a si (preocupação).

Permeadas pelos conceitos heideggerianos de poderser, existência e ser-no-mundo, Magnan e Feijoo trazem a importante consideração de que decidir e escolher se articulam mas não são sinônimos: decisão é um horizonte de abertura no qual a escolha acontece.

No contato com as obras de Rainer Maria Rilke e Kierkegaard, Cartas a um jovem poeta e A repetição, respectivamente, é pontuado que em ambos compreende-se que a tarefa de orientar implica saber que a tarefa de escolher é sempre arriscada e que esse risco deve ser assumido por aquele que escolhe.

Mediante esta fundamentação filosófica e literária, as autoras afirmam que a proposta em Análise da Escolha Profissional por elas defendida busca assumir "a postura de resgatar o espaço da possibilidade de que o analisando possa ver a si mesmo, julgar-se por si mesmo, podendo encontrar, na tessitura de sua existência, a sua medida" (p. 104. Grifo do autor). O termo análise é tomado em seu sentido grego indicando "o desfazer de uma trama em seus componentes" (p. 109).

Dessa forma, concebe-se que o processo de Análise da Escolha Profissional vai acontecendo, respeitando o modo de ser de cada analisando, valorizando o que este elege como significativo em sua existência, mas sem se esquecer do caráter fundante de indeterminação próprio do poder-ser, da abertura, em que cada pessoa sempre se encontra.

A escolha das autoras pelo caminho fenomenológico-existencial possibilita uma ação psicológica não mais voltada para a teoria explicativa e objetivista da realidade, tampouco, uma instrumentalização da prática e uma noção representacional da verdade. Em lugar disso, propõe-se olhar para o humano em seu acontecimento no fluxo espaço-temporal do vivido. Olhar para o homem tal como ele se apresenta em seu momento, em sua intencionalidade. Destarte, qualquer noção de vocação como algo inato a ser encontrada é colocada em 
suspensão, bem como as teorias modernas dicotômicas. A questão que se coloca na escolha profissional é ter de fazer algo com a existência que é do humano e que só ele pode ocupar-se dela.

Em conclusão, destaca-se o mérito das autoras em adotarem uma linguagem acessível e esclarecedora, apesar da complexidade da temática proposta acerca da importância de uma análise da escolha profissional conforme apresentada, o que ressalta a relevância dessa obra. Também vale destacar sua enorme contribuição para o desenvolvimento da psicologia e para a prática clínica ao possibilitar ao analisando, através da fusão de horizontes com o analista, um pre-ocupar-se com a própria existência. 